\title{
A REVIEW ON NASAL DRUG DELIVERY SYSTEM AND ITS CONTRIBUTION IN THERAPEUTIC MANAGEMENT
}

\author{
SULAIMAN ALNASSER* \\ Department of Pharmacology and Toxicology, Unaizah College of Pharmacy, Qassim University, Unaizah, Saudi Arabia. \\ Email: sm.alnasser@qu.edu.sa
}

Received: 01 September 2018, Revised and Accepted: 05 December 2018

\begin{abstract}
Nasal drug delivery has received a great deal of attention as a convenient, reliable, and promising method for the systemic administration of drugs. It is especially for those molecules which are ineffective orally and only effective if administered by injection. The nasal route of drug delivery has advantages over the other alternative systems of non-invasive drug administration. The present review describes nasal delivery systems in recognizing to its potential and limits. The present review is an attempt to provide some information concerning nasal drug delivery system such as limitations, advantages, mechanism of drug absorption, anatomy of nasal cavity, factors affecting of nasal drug delivery, strategies to enhance nasal absorption, strategies to extend duration of drug formulations within the nasal cavity, leading to improved nasal drug absorption, novel drug formulations, sorts of nasal drug delivery system with uses of nasal drug delivery in various diseases, and recent advancement of nasal delivery systems.
\end{abstract}

Keywords: Nasal drug delivery systems, Non-invasive drug administration, Anatomy and physiology, Recent advancement.

(C) 2019 The Authors. Published by Innovare Academic Sciences Pvt Ltd. This is an open access article under the CC BY license (http://creativecommons. org/licenses/by/4. 0/) DOI: http://dx.doi.org/10.22159/ajpcr.2019.v12i1.29443

\section{INTRODUCTION}

In recent time, the nasal drug delivery received a great deal of attention for its convenient, promising, and reliable way of systemic administration for drugs, especially for those drugs which are ineffective orally and those which must be administered by injections. This route provides a large surface area, porous endothelial membrane, high total blood flow, bypassing the first-pass metabolism, and ready accessibility. Furthermore, nasal mucosa is permeable to more compounds than the gastrointestinal tract due to the absence of pancreatic, gastric enzymatic activities, and interference by gastrointestinal contents. The early recorded historical application of nasal drug delivery was restricted to topical applications of drugs intended for only local effects. However in recent times, its application grown to include a wide range of targeted areas in the body to produce local and systemic effects. Nasal drug delivery also finds a special place in the traditional system of medicine such as the Ayurvedic system of Indian medicine which is called as "Nasya karma" and is a wellrecognized way of treatment [1-4].

In therapeutics, nose forms an important part of the body for faster and higher level of drug absorption with the possibility of self-administration. Drugs are ranging from small micromolecules to large macromolecules such as peptide/proteins, hormones, and vaccines, are being delivered through the nasal cavity. It is reported that lipophilic drugs are generally well absorbed from the nasal cavity with pharmacokinetic profiles often identical to those obtained following an intravenous injection with a bioavailability approaching up to $100 \%$ in many cases. Large absorption surface area and high vascularization lead to fast absorption. In emergency, nasal route can be used as a substitute route of parenteral administration [5-8]. Drugs are rapidly absorbed from the nasal cavity after intranasal administration, resulting in rapid systemic drug absorption. An approach if made for increasing the residence time of drug formulations in the nasal cavity can result in improved nasal drug absorption. Depending on the desired site of drug action, the drug to be inhaled needs to be adjusted to particle size, concentration, and chemical form to ensure a local or systemic drug action.

\section{POSSIBILITIES FOR THE USE OF THE NASAL CAVITY FOR DRUG} DELIVERY

The easy accessibility and available surface area make the nose a possibly viable drug delivery organ. Pharmaceutical product development is an essential task which is directly dependent on its therapeutic objectives. The aspects to be considered for product development depend on whether it is intended for:

a) Local delivery

b) Systemic delivery

c) Single or repetitive administration.

Local delivery

Nasal delivery is a logical delivery choice for local (or topical) treatment as it provides the minimal potential for systemic adverse effects when compared to the oral route of administration, and hence, relatively low doses are effective when administered through nasal route with less systemic toxic effects. Prominent therapeutic classes of drugs delivered are decongestants for cold nasal symptoms and antihistamines and corticosteroids for allergic rhinitis $[9,10]$.

\section{Systemic delivery}

The intranasal administration of drugs is an effective way for the systemic availability of drugs as compared to oral and intravascular routes of administration. It provided fast and extended drug absorption than oral and parenteral administration. Therapeutic classes of drugs delivered include analgesics (exmorphine), cardiovascular drugs as propranolol and carvedilol, hormones such as levonorgestrel, progesterone, and insulin, anti-inflammatory agents as indomethacin and ketorolac, and antiviral drugs (acyclovir). Some examples which are available in the market include zolmitriptan and sumatriptan for the treatment of a migraine and cluster headaches $[9,11-15]$.

\section{Nasal vaccines}

During inhalation nasal mucosa is the first site of contact with inhaled antigens, and therefore, its use for vaccination, especially for respiratory infections, has been extensively evaluated. In fact, nasal vaccination is a promising alternative to the classic parenteral route because it can enhance the systemic levels of specific immunoglobulin 
$\mathrm{G}$ and nasal secretory immunoglobulin A. Examples of the human efficacy of intranasal vaccines include those against influenza A and B virus, proteosoma-influenza, adenovirus-vectored influenza, Group B meningococcal native, attenuated respiratory syncytial virus, and parainfluenza 3 virus $[9,16-19]$.

\section{CENTRAL NERVOUS SYSTEM (CNS) DELIVERY THROUGH NASAL ROUTE}

The intranasal route has encouraging approach for the delivery of drugs to the brain. The delivery of drugs to CNS from the nasal route may occur through olfactory neuroepithelium. Drug delivery through nasal route into CNS has been reported for Alzheimer's disease, brain tumors, epilepsy, pain, and sleep disorders [20,21,22,23]

\section{ANATOMICAL AND PHYSIOLOGICAL CONSIDERATION FOR INTRANASAL DELIVERY}

\section{Anatomy}

The human skull is composed of two active sections for protecting the delicate structures within it. One of them, is the neurocranium which surrounds and protects the brain while the other, viscerocranium composed of several bones that form the skeleton of the face as well as parts of the jaw offering protection to eyes, mouth and the nasal cavity $[24,25]$. Nasal cavity can anatomically be segregated into five different regions: The nasal vestibule, atrium, respiratory area, olfactory region, and the nasopharynx Table 1 . The nasal cavity is divided into two symmetrical halves by the nasal septum (comprised bone and cartilage), each cavity has volume up to approximately $7.5 \mathrm{~mL}$ and a surface area around $75 \mathrm{~cm}^{2}$. The nasal cavity extends posteriorly to the nasopharynx. The most anterior part of the nasal cavity, the nasal vestibule opens at the face through the nostrils. The atrium is an intermediate region between the vestibule and the respiratory region. The respiratory region occupies the major part of the nasal cavity which possesses lateral walls dividing it into three sections: Inferior (C1), middle (C2), and superior (C4) nasal turbinates. These folds provide the nasal cavity with a very high surface area of about $150 \mathrm{~cm}^{2}$ in humans compared to its small volume. The respiratory region is richly supplied with blood, and receives the maximum amount of nasal secretions, rendering it most suitable for the permeation of compounds. The olfactory region situated above the superior nasal turbinate which possesses ciliated olfactory nerve cells for smell perception. The total surface area of the olfactory epithelium is about $200-400 \mathrm{~mm}^{2}[24,26,27,28]$.

The systemic circulation using nasal drug delivery was as follows:

1. Hepatic first-pass metabolism is avoided.

2. Improving patient compliance compared to parenteral routes as easy accessibility and needle-free drug application without the presence of trained personnel facilitates self-medication.

3. Drug degradation that is observed in the gastrointestinal tract can be bypass.

4. Using absorption enhancer, the bioavailability of large drug molecules can be improved through nasal route.

5. Rapid drug absorption and quick onset of action can be achieved easily.

6. Bioavailability though nasal route for smaller drug molecules is good.

7. Drug possessing poor stability in GIT fluids is given by nasal route.

8. Studies reveal that the nasal route is an alternate to parenteral route, especially, for protein and peptide drugs.

9. A polar compound exhibiting poor oral absorption may be particularly suited for this route of delivery.

10. Convenient for the patients, especially for those on long-term therapy, when compared with parenteral medication.

Disadvantages [29-31]

1. The nasal cavity provides a smaller absorption surface area when compared to gastrointestinal tract.

2. There is a possibility of irritation when compared to the oral delivery system since.

3. The substance and constituents added to the dosage form may cause local side effects and irreversible damage of the cilia on the nasal mucosa.

4. There could be a mechanical loss of the dosage form into the other parts of the respiratory tract like lungs due to the improper technique of administration.

5. Certain surfactants used as chemical enhancers may disrupt and even dissolve the membrane in high concentration.

Limitations of nasal drug delivery [32,29-31,33]

1. There is a risk of both of irreversible damage of the cilia of the nasal mucosa and local side effects from both constituents and substances additional to the dosage form.

2. There can be a mechanical loss of the dosage form in other parts of the respiratory system, for example, lungs due to the inappropriate technique of administration.

3. Some of the surfactants used as a chemical catalyst and may cause or even dissolve the membrane at high concentrations.

Advantages of nasal drug delivery [32,29-31,33,34,35]

- Drugs that are orally not absorbed can be delivered to volume that can be delivered into nasal cavity are restricted to $25-200 \mu \mathrm{L}$

1. High-molecular-weight compounds cannot be delivered through this route (mass cut off $\sim 1 \mathrm{kDa}$ )

2. Adversely affected by pathological conditions.

Table 1: Structural features of various regions and their impact on the permeability of nasal cavity

\begin{tabular}{|c|c|c|}
\hline Region & Structural features & Permeability \\
\hline Nasal vestibule & $\begin{array}{l}\text { Nasal hairs (vibrissae) } \\
\text { Epithelial cells are stratified, squamous, and keratinized } \\
\text { Sebaceous glands present }\end{array}$ & $\begin{array}{l}\text { Least permeable due to the presence of } \\
\text { keratinized cells, very resistant to hydration } \\
\text { and can withstand insults from noxious } \\
\text { substances of the environment }\end{array}$ \\
\hline Atrium & $\begin{array}{l}\text { Transepithelial region } \\
\text { Stratified squamous cells present anteriorly and } \\
\text { pseudostratified cells with microvilli present posteriorly } \\
\text { The narrowest region of the nasal cavity }\end{array}$ & $\begin{array}{l}\text { Less permeable as it has small surface area and } \\
\text { stratified cells are present anteriorly }\end{array}$ \\
\hline $\begin{array}{l}\text { Respiratory region (inferior } \\
\text { turbinate middle turbinate } \\
\text { superior turbinate) }\end{array}$ & $\begin{array}{l}\text { Pseudostratified ciliated columnar cells with microvilli ( } 300 \text { per } \\
\text { cell), large surface area } \\
\text { Receives maximum nasal secretions due to the presence of } \\
\text { seromucous glands, nasolacrimal duct, and goblet cells } \\
\text { Richly supplied with blood for heating and humidification of } \\
\text { inspired air, the presence of paranasal sinuses }\end{array}$ & $\begin{array}{l}\text { Most permeable region due to large surface } \\
\text { area and rich vasculature }\end{array}$ \\
\hline Olfactory region & $\begin{array}{l}\text { Specialized ciliated olfactory nerve cells for smell perception } \\
\text { Receives ophthalmic and maxillary divisions of the trigeminal } \\
\text { nerve }\end{array}$ & Direct access to cerebrospinal fluid \\
\hline Nasopharynx & $\begin{array}{l}\text { The upper part contains ciliated cells, and the lower part } \\
\text { contains squamous epithelium }\end{array}$ & Receives nasal cavity drainage \\
\hline
\end{tabular}


3. Large interspecies variability is observed in this route.

4. Normal defense mechanisms such as mucociliary clearance and ciliary beating affect the permeability of the drug.

5. The enzymatic barrier to the permeability of drugs.

6. Irritation of nasal mucosa by drugs.

7. Limited understanding of mechanisms and less developed models at this stage.

8. Enhanced patient compliances.

9. Decrease risk of overdose.

10. Fast onset of therapeutic action. Factor affecting nasal drug absorption. The rate and extent of nasal absorption of a drug are dependent on various factors listed in Table 2 . The factors that can influence drug absorption from the nasal cavity are very important in designing both formulation and the device used for intranasal administration [36,37,38,39].

\section{MECHANISM OF NASAL DRUG ABSORPTION}

Two mechanisms have been considered predominantly out of several mechanisms that have been proposed.

The first involves an aqueous route of transport, which is also known as the paracellular route. Key feature of this mechanism involves

- This route is slow and passive.

- There is an inverse log-log correlation between intranasal absorption and the molecular weight of water-soluble compounds.

- Poor bioavailability was observed for a drug with a molecular weight greater than 1000 Daltons

The second involves transport through a lipoidal route is also known as the transcellular process and is responsible for the transport of lipophilic drugs that show a rate dependency on their lipophilicity. For examples, chitosan, a natural biopolymer from shellfish, opens tight junctions between epithelial cells to facilitate drug transport $[40,41,42]$.

\section{STRATEGIES FOR IMPROVING DRUG AVAILABILITY IN NASAL DELIVERY}

Various strategies used to improve the availability of the drug in the nasal mucosa include:

1. Nasal residence time improvement
2. Nasal absorption enhancement

3. Modification of drug structure to change its physicochemical properties $[43,44,45]$

\section{To improve the nasal residence time}

Mucociliary clearance acts to remove the foreign bodies and substances from nasal mucosa as quickly as possible. One way of delaying clearance is to apply the drug to the anterior part of the nasal cavity, an effect that is largely determined by the type of dosage form used. The preparation could also be formulated with polymers such as methylcellulose, hydroxy propyl methyl cellulose or polyacrylic acid also with Various compounds used as an enhancer in nasal drug delivery research of nasal drug delivery systems listed in Table 3, in which incorporation ofthe polymer increases the viscosity of the formulation and also acts as a bio-adhesive with mucus.Increase in residence time does not necessarily lead to an increase the absorption; this concept can be illustrated by considering insulin solution with similar viscosity containing carbopol and carboxymethylcellulose (CMC). Here, carbopol enhances the absorption, whereas CMC solution does not enhance the absorption of insulin. If we increase the viscosity, slow diffusion of the drug from matrix causes retention in absorption with CMC. In case of carbopol causes enhancement of absorption due to opening the intracellular junctions. One more lucrative way to increase the nasal resistance time is using biodegradable microspheres as a carrier for drug delivery. Biodegradable microspheres swell in the presence of water, thereby increasing the viscosity. This phenomenon leads to increase the nasal residential time.

\section{Enhancing nasal absorption}

It is possible to greatly improve the nasal absorption of polar drugs by administering them in combination within an absorption enhancer that promotes the transport of the drug across the nasal membrane. Furthermore, a nasal drug delivery system that combines an absorption enhancing activity with a bioadhesive effect, which increases the residence time of the formulation in the nasal cavity, has been shown to be even more effective for improving the nasal absorption of polar drugs. A wide range of absorption enhancer systems has been evaluated in animal models (and some in man). Certainly, in animal models, they have been shown to improve significantly the nasal absorption of drugs. Animal models, such as the rabbit and even the dog, can give

Table 2: Factors influencing intranasal drug delivery

\begin{tabular}{|c|c|c|}
\hline Biological factors & Formulation-related factors & Strategies to overcome them \\
\hline Biochemical changes & Physicochemical properties of the drug & Prodrugs \\
\hline Refer to the enzymatic barrier of nasal mucus & Lipophilicity & Enzyme inhibitors Absorption \\
\hline Which include oxidative and conjugative & Chemical form & enhancers Mucoadhesive drug \\
\hline Enzymes, peptidases, and proteases & Polymorphism & delivery systems \\
\hline Physiological factors & Molecular weight & Novel formulation forms \\
\hline Blood supply and neuronal regulation & Partition coefficient and pKa & \\
\hline Nasal secretions & Solubility and dissolution rate & \\
\hline Nasal cycle & Physicochemical properties of formulation & \\
\hline $\mathrm{pH}$ of the nasal cavity & pH and mucosal irritancy & \\
\hline Mucociliary clearance and ciliary beat frequency & Osmolarity & \\
\hline Pathological conditions & Viscosity/density & \\
\hline Common cold & Drug distribution & \\
\hline Rhinitis & Area of nasal membrane exposed & \\
\hline Atrophic rhinitis & Area of solution applied & \\
\hline Nasal polyposis & Dosage form & \\
\hline Temperature & Types of dosage form and delivery systems & \\
\hline \multirow[t]{7}{*}{ Humidity } & Nasal drops & \\
\hline & Solution sprays & \\
\hline & Suspension sprays & \\
\hline & Powders & \\
\hline & Gels & \\
\hline & Emulsions and ointments & \\
\hline & Specialized systems, for example, microspheres, & \\
\hline
\end{tabular}


Table 3: Various compounds used as an enhancer in nasal drug delivery research of nasal drug delivery systems

\begin{tabular}{ll}
\hline Name of compound & Example \\
\hline Surfactants & $\begin{array}{l}\text { SDS, polyoxyethylene-9-laurylether, } \\
\text { phosphatidylcholines } \\
\text { EDTA }\end{array}$ \\
$\begin{array}{l}\text { Complexing and chelating } \\
\text { Cyents }\end{array}$ & $\alpha-, \beta-, \gamma$-cyclodextrin, DM $\beta$-, \\
Fusidic acid derivative & $\begin{array}{l}\text { HP } \beta \text {-cyclodextrin } \\
\text { STDHF } \\
\text { Bile salts }\end{array}$ \\
$\begin{array}{l}\text { Sodium taurocholate, sodium } \\
\text { glycocholate } \\
\text { Degradable starch microsphere, } \\
\text { dextran microspheres }\end{array}$ \\
\hline
\end{tabular}

SDS: Sodium dodecyl sulfate, EDTA: Ethylenediaminetetraacetic acid,

STDHF: Sodium tauradihydrofusidate

leading results, most probably a result of the different architecture and morphology of the nasal cavity and also the use of anesthetics or sedating procedures that can affect the mucociliary clearance mechanism $[46,47,48]$. As an example, some years ago $[49,50,51-53]$ published results from a study on the nasal delivery of insulin using the rat model with dimethyl- $\beta$-cyclodextrin as the absorption enhancer. They obtained an astonishing bioavailability of $100 \%$ when compared with a subcutaneous injection of insulin. Later, when the same formulation was tested in rabbits and man, the resulting bioavailability in both animal species was almost $0 \%$. Second, enhancers, such as surfactants, bile salts, fatty acids, and most phospholipids and lysophospholipids, can work by modifying the phospholipid bilayer structure of cells, leaching out proteins or even stripping off the outer layer of the mucosa, thereby promoting the observed improved transcellular transport of drugs. In general, for such enhancer systems, there is a direct correlation between the bioavailability obtained and damage caused to the membrane $[54,55,56]$. For other enhancers, especially those that work by transiently opening the tight junctions between the cells (e.g., chitosan, see later) and selected cyclodextrins and phospholipids, the absorption enhancing effect can greatly outweigh any modifications caused to the mucosa. The absorption enhancement mechanisms can be grouped into two classes: Physicochemical effects: Some enhancers can alter the physicochemical properties of a drug in the formulation. This can happen by altering the drug solubility, drug partition coefficient, or by weak ionic interactions with the drug and membrane effects: Many enhancers show their effects by affecting the nasal mucosa surface $[29,42]$.

\section{Modifying drug structure}

Modification of drug structure without altering pharmacological activity is one of the lucrative ways to improve the nasal absorption. Here, a modification of physiochemical properties such as molecular size, molecular weight, $\mathrm{pKa}$, and solubility is favorable for nasal drug absorption [21,55-58].

Designing of nasal formulation depends on the therapeutic need of the particular drug molecule, duration of action, and duration of therapy. Both controlled release and conventional release drug delivery are possible through nasal route. The requirement of the pharmaceutical excipients depends on the mode of drug delivery, that is, local or systemic drug delivery [59-63]. A wide range of nasal formulations are available and many studies have been done so far, some of these delivery systems and their key features are summarized below.

\section{Nasal drops}

They are the most convenient and simple system developed for nasal drug delivery. Nose drops can be delivered with a squeezy or by a pipette a bottle. These pharmaceuticals formulations are often recommended for treating local conditions, which include suffering some challenges such as microbial growth, mucosal dysfunction, and non-specific loss of the nose or lower back [61-66]. The featured disadvantage of this system is the lack of the dose precision, and therefore, nasal drops may not be useful for prescription products. It has been reported that nasal drops deposit human serum albumin in the nostrils more efficiently than nasal sprays.

\section{Nasal sprays}

Solution and suspension are formulated into nasal sprays. Availability of metered dose pumps and actuators, a nasal spray can deliver an exact dose from 25 to $200 \mu \mathrm{m}$. The morphology particles size (for suspensions) of the drug and viscosity of the formulation determine the choice of pump and actuator assembly $[61,62,65,67]$.

\section{Nasal gels}

Until the recent development of precise dosing device, there was not a lot of interest during this system. Nasal gels are high viscosity thickened solutions or suspensions. The benefits of a nasal gel include the reduction of post-nasal drip due to high viscosity, reduction of taste impact due to reduced swallowing, reduction of anterior leakage of the formulation, reduction of irritation using soothing/emollient excipients, and target to mucosa for higher absorption $[61,65,67,68,23]$.

\section{Nasal powder}

This dosage form may be formulated if solution and suspension dosage forms cannot be formulated, for example, due to lack of drug stability. The advantages to the nasal powder dosage form are the absence of superior stability and preservative of the formulation. However, the suitability of the powder formulation is dependent on the solubility, particles size, aerodynamic properties, and nasal irritancy of the active drug and excipients. Local application of the drug is another advantage of this system $[35,39,61,65,67,70]$.

\section{Liposomes}

These are phospholipid vesicles composed by bilayer enclosing one or more aqueous compartments, in these compartments drug can be entrapped or adsorbed.

\section{Microspheres}

Microsphere has an important role in nasal drug delivery with enhancing absorption, sustained release, and also has great importance because it protects the drug from enzymatic degradation [34].

\section{EVALUATION OF NASAL FORMULATIONS}

To improving the efficiency and effectiveness of active principles, formulations, and devices, another important objective of the pharmaceutical research is improving the link between in vitro test data and in vivo performance. In this way, the helpful dialogue among manufacturing, regulators, and academic investigators, which already started with workshops concerning bioequivalence, is continuing. These formal attitudes are most likely to reflect those involved in the development of oral or nasal inhalation orally inhaled and nasal drug products, and this reflex is often given special attention to their design and analytical control $[34,69,70]$.

\section{In vitro nasal permeation studies}

Various methods are used to determine the drug diffusion through nasal mucosa from the formulation.

The two most important ways to study the diffusion profile of the drug are discussed below.

\section{In vitro diffusion studies}

The nasal diffusion cell is fabricated in the glass. The water-jacketed recipient chamber has a total capacity of $60 \mathrm{ml}$ and a flanged top of about $3 \mathrm{~mm}$; the lid has three opening, each for sampling, thermometer, and a donor tube chamber. The $10 \mathrm{~cm}$ long donor chamber and a donor 
tube chamber has a total capacity of $60 \mathrm{ml}$ and a flanged top of about $3 \mathrm{~mm}$; the lid has three openings, each for sampling, thermometer, and a donor tube chamber. The $10 \mathrm{~cm}$ long donor chamber tube has an internal diameter of $1.13 \mathrm{~cm}$. The nasal mucosa of sheep was separated from sublayer bony tissues and stoned in distilled water containing few drops at gentamicin injection. After the complete removal of blood from mucosal surface, is attached to the donor chamber tube. The donor chamber tube is placed such a way that it just touches the diffusion medium in recipient chamber. At predetermined intervals, samples $(0.5 \mathrm{ml})$ from recipient chamber are with a draw and transferred to amber colored ampoules. The samples withdrawn are suitably replaced. The samples are estimated for drug content by a suitable analytical technique. Throughout the experiment, the temperature is maintained at $37^{\circ} \mathrm{C}[61,69-71]$, in vitro, one study showed that almost $95.2 \%$ drug was released from the formulation within $2 \mathrm{~min}$ [72].

\section{In vivo nasal absorption studies}

\section{Animal models for nasal absorption studies}

The animal models employed for nasal absorption studies can be of two types, namely whole animal or in vivo model and isolated organ perfusion or ex vivo model.

In vivo models are rat model, rabbit model, monkey model, and dog model $[62,70,73,74]$.

\section{Ex vivo nasal perfusion models}

Surgical preparation is that the same as that is for in vivo rat model. During the perfusion studies, a funnel is placed between the nose and reservoir to minimize the loss of the drug solution. The drug solution is placed in a reservoir maintained at $37^{\circ} \mathrm{C}$ and is circulated through the nasal cavity of the rat with a peristaltic pump. The perfusion solution passes out from the nostrils (through the funnel) and runs once more into the reservoir. The drug solution within the reservoir is continuously stirred. The amount of drug absorbed is estimated by measuring the residual drug concentration within the perfusing solution. The drug activity due to stability problems may be lost during experiment. This is especially true for peptide and protein drugs that may undergo proteolysis and aggregation. Rabbit may be used as the animal model for ex vivo nasal perfusion studies. The rabbit is anesthetized with parenteral urethane-acepromazine. A midline incision is made in the neck, and the trachea is cannulated with a polyethylene neonatal endotracheal tube. The esophagus is isolated and ligated. The distal end of the esophagus is closed with suture, and flexible Tygon tubing is inserted into the proximal end and advanced to the posterior part of the nasal cavity. The nasopalatine tract (that connects the nasal cavity to the mouth) is closed with an adhesive to avoid drainage of drug solution from the nasal cavity. The drug in the isotonic buffer solution is recirculated using a peristaltic pump [62,60,70,75-77].

\section{CONCLUSION}

The nasal cavity has a large surface area and a highly vascularized mucosa. Drugs absorbed by the rich network of blood vessels pass directly into the systemic circulation, thereby avoiding the firstpass metabolism. A growing body of evidence relating to nasal drug delivery suggests it might use for challenging drugs which can facilitate the pharmaceutical manufacturing and drug delivery challenges. Considering the wealth of activity and interest in the area of nasal drug delivery, together with the potential benefits from this route of administration, we should expect to see a range of novel nasal products reaching the market shortly.

\section{Future needs and further research and development}

It is not surprising to find a lot of research focusing to develop nasal drug delivery system and its contribution in therapeutic management. In general, a concise overview of the pharmacotherapy of nasal drug delivery system has highlighted that in spite of the availability of new drugs and several specialized devices.

\section{ACKNOWLEDGMENT}

I thank Dr. Shalam M.Hussain, Associate Professor, Department of Pharmacology, Unaizah College of Pharmacy, Qassim University, for his assistance in conceptualizing the idea for the present manuscript and helping me in initial feedback on this manuscript.

\section{AUTHOR'S CONTRIBUTION}

Sulaiman Alnasser planned the study and collected the data for the write up, reviewed, and prepared the final manuscript.

\section{CONFLICTS OF INTEREST STATEMENT}

Author reports none.

\section{REFERENCES}

1. Hicke AJ. Pharmaceutical Inhalation Aerosol Technology. $2^{\text {nd }}$ ed. New York: Marcel Dekker, Inc.; 2004.

2. Sharma PK, Chaudhari P, Kolsure P, Ajab A, Varia N. Recenttrends in nasal drug delivery system - An overview. ARPB 2006;5:4.

3. Ramadan HH, Sanclement JA, Thomas JG. Chronic rhinosinusitis and biofilms. Otolaryngol Head Neck Surg 2005;132:414-7.

4. Mahita B, Vinod K. A clinic opathological study of allergic rhinitis. Asian J Pharm Clin Res 2017;10:186-91.

5. Shanu T, Nitin S, Sharma PK. A review on application of natural bio adhesive polysaccharides for intranasal drug delivery. Int J A.PS.BMS 2012;1:80-94

6. Zaheer A, Swamy S. Mucoadhesive polymers: Drug carriers for improved nasal drug delivery. Indian J Novel Drug Deliv 2012;4:2-16.

7. Vyas SP, Khar RK. Targeted and Controlled Drug Delivery Novel Carrier System. $1^{\text {st }}$ ed. New Delhi: CBS Publishers and Distributors; 2006. p. 173, 249, 331, 417.

8. Mahalaxmi R, Kumar DS, Shirwaikar A. preparation of mucoadhesive microsphere for nasal delivery by spray drying. Indian J Pharm Sci 2007;69:651-7.

9. Pires A, Fortuna A, Alves G, Falcão A. Intranasal drug delivery: How, why and what for? J Pharm Pharm Sci 2009;12:288-311.

10. Varshosaz J, Sadrai H, Heidari A. Nasal delivery of insulin using bioadhesive chitosan gels. Drug Deliv 2006;13:31-8.

11. Stoker DG, Reber KR, Waltzman LS, Ernst C, Hamilton D, Gawarecki D, et al. Analgesic efficacy and safety of morphine-chitosan nasal solution in patients with moderate to severe pain following orthopedic surgery. Pain Med 2008;9:3-12.

12. Patil SB, Sawant KK. Development, optimization and in vitro evaluation of alginate mucoadhesive microspheres of carvedilol for nasal delivery. J Microencapsul 2009;26:432-43

13. Ding WX, Qi XR, Fu Q, Piao HS. Pharmacokinetics and pharmacodynamics of sterylglucoside-modified liposomes for levonorgestrel delivery via nasal route. Drug Deliv 2007;14:101-4.

14. Costantino HR, Illum L, Brandt G, Johnson PH, Quay SC. Intranasal delivery: Physicochemical and therapeutic aspects. Int $\mathrm{J}$ Pharm 2007;337:1-24.

15. Langley JM, Halperin SA, McNeil S, Smith B, Jones T, Burt D, et al. Safety and immunogenicity of a proteosome -trivalent inactivated influenza vaccine, given nasally to healthy adults. Vaccine 2006;24:1601-8.

16. Van Kampen KR, Shi Z, Gao P, Zhang J, Foster KW, Chen DT, et al. Safety and immunogenicity of adenovirus-vectored nasal and epicutaneous influenza vaccines in humans. Vaccine 2005;23:1029-36.

17. Greenberg DP, Walker RE, Lee MS, Reisinger KS, Ward JI, Yogev R, et al. A bovine parainfluenza virus type 3 vaccine is safe and immunogenic in early infancy. J Infect Dis 2005;191:1116-22.

18. Garmise RJ, Staats HF, Hickey AJ. Novel dry powder preparations of whole inactivated influenza virus for nasal vaccination. AAPS Pharm Sci Tech 2007;8:E81.

19. Ugwoke MI, Verbeke N, Kinget R. The biopharmaceutical aspects of nasal mucoadhesive drug delivery. J Pharm Pharmacol 2001;53:3-21.

20. Illum L. Transport of drugs from the nasal cavity to the central nervous system. Eur J Pharm Sci 2000;11:1-8.

21. Merkus P, Ebbens FA, Muller B, Fokkens WJ. The 'best method' of topical nasal drug delivery: Comparison of seven techniques. Rhinology 2006;44:102-7.

22. Al-Ghananeem AM, Sandefer EP, Doll WJ, Page RC, Chang Y, Digenis GA, et al. Gamma scintigraphy for testing bioequivalence: A case study on two cromolyn sodium nasal spray preparations. Int J Pharm 2008;357:70-6.

23. Kritika S, Bhupen K, Banasmita K. Development and characterization 
of mucoadhesive microsphere-loaded intranasal gel of venlafaxine hydrochloride. Asian J Pharm Clin Res 2016;9:139-44.

24. Wüthrich $P$, Buri $P$. The transnasal route of drug administration. Aspects of nasal anatomy and physiology. Pharm Acta Helv 1989;64:322-31.

25. Marple B, Roland P, Benninger M. Safety review of benzalkonium chloride used as a preservative in intranasal solutions: An overview of conflicting data and opinions. Otolaryngol Head Neck Surg 2004;130:131-41.

26. Fokkens WJ. Unmet needs in rhinology. Rhinology 2008;46:257-8.

27. Frank DO, Kimbell JS, Pawar S, Rhee JS. Effects of anatomy and particle size on nasal sprays and nebulizers. Otolaryngol Head Neck Surg 2012;146:313-9.

28. Guo Y, Laube B, Dalby R. The effect of formulation variables and breathing patterns on the site of nasal deposition in an anatomically correct model. Pharm Res 2005;22:1871-8.

29. Illum L. Nasal delivery. The use of animal models to predict performance in man. J Drug Target 1996;3:427-42.

30. Dey S, Mahanti B, Mazumder B, Malgope A, Dasgupta S. Nasal drug delivery: An approach of drug delivery through nasal route. Pelagia Res Lib 2011;2:94-106.

31. Molinari G, Colombo G, Celenza C. Respiratory allergies: A general overview of remedies, delivery systems, and the need to progress. ISRN Allergy 2014;2014:326980.

32. Chirag P, Tyagi S, Mangukia D, Ishita S, Shreya P, Pinkesh P, et al. A recent review on alternative system of parenteral delivery: Nasal drug delivery system. J Drug Discov Ther 2013;1:12-8.

33. Dale O, Nilsen T, Loftsson T, Hjorth Tønnesen H, Klepstad P, Kaasa S, et al. Intranasal midazolam: A comparison of two delivery devices in human volunteers. J Pharm Pharmacol 2006;58:1311-8.

34. Özer AY. The importance of intranasal route for application of drugs and nasal drug delivery systems. Pharm JTPA 1990;30:136-47.

35. Ravikumar R, Balan R, Ganesan N, Thiruvengadam D. Recent modalities in drug delivery via inhalation therapy - An advanced treatment strategy for pulmonary carcinoma. Int J Pharm Pharm Sci 2015;7:8-21.

36. Kublik H, Vidgren MT. Nasal delivery systems and their effect ondeposition and absorption. Adv Drug Deliv Rev 1998;29:157-77.

37. Benninger MS, Hadley JA, Osguthorpe JD, Marple BF, Leopold DA, Derebery MJ, et al. Techniques of intranasal steroid use. Otolaryngol Head Neck Surg 2004;130:5-24.

38. Newman SP, Morén F, Clarke SW. Deposition pattern of nasal sprays in man. Rhinology 1988;26:111-20.

39. Mosab A. Approaches to achieve an oral controlled release drug delivery system using polymers: A recent review. Int J Pharm Pharm Sci 2025;7:16-21.

40. Aulton ME. Pharmaceutics - The Science of Dosage form Design. New York: Churchill Livingston; 2002. p. 494.

41. Johnson NJ, Hanson LR, Frey WH. Trigeminal pathways deliver a low molecular weight drug from the nose to the brain and orofacial structures. Mol Pharm 2010;7:884-93.

42. Svensson S, Olin AC, Hellgren J. Increased net water loss by oral compared to nasal expiration in healthy subjects. Rhinology 2006; 44:74-7.

43. Talegaonkar S, Mishra PR. Intranasal delivery: An approach to bypass the blood brainbarrier. Indian J Pharm 2004;36:140-7.

44. Hussein NR. Bioadhesive Microparticles and Liposomes of AntiParkinson Drugs for Nasal Delivery. Ph.D. Thesis, University of Central Lancashire; 2014.

45. Chajed S, Sangle S, Barhate S. Advantagious nasal drug delivery system - A review. Int J Pharm Sci Res 2011;2:1322-6.

46. Kumar PT, Vani MI, Yamini D, Raju PN, Reddy G. Recent advances in nasal formulations and devices used in pulmonary drug delivery. World J Pharm Pharm Sci 2013;2:3759-78

47. Inthavong K, Ge Q, Se CMK, Yang W, Tu JY. Simulation of sprayed particle deposition in a human nasal cavity including a nasal spray device. J Aerosol Sci 2011;42:100-13.

48. Darquenne C. Aerosol deposition in health and disease. J Aerosol Med Pulm Drug Deliv 2012;25:140-7.

49. Aurora J. Development of nasal delivery systems. A review. Drug Deliv Technol 2002;2:1-8

50. Duquesnoy C, Mamet JP, Sumner D, Fuseau E. Comparative clinical pharmacokinetics of single doses of sumatriptan following subcutaneous, oral, rectal and intranasal administration. Eur J Pharm Sci 1998;6:99-104.

51. Luthringer R, Djupesland PG, Sheldrake CD, Flint A, Boeijinga P, Danjou P, et al. Rapid absorption of sumatriptan powder and effects on glyceryl trinitrate model of headache following intranasal delivery using a novel bi-directional device. J Pharm Pharmacol 2009;61:1219-28.

52. Sommer F, Kroger R, Lindemann J. Numerical simulation of humidification and heating during inspiration within an adult nose. Rhinology 2012;50:157-64.

53. Kleven M. Numerical Simulations and Experimental Studies for Nasal Delivery of Vaccines and Drugs. Thesis. NTNU; 2012. ISBN:978-82471-3398-9.

54. Illum L. Bioadhesive formulations for nasal peptide delivery. In: Mathiowitz E, Chickering DE, Lehr CM, editors. Drug Delivery Issues in Fundamentals, Novel Approaches, and Development. New York: Marcel Dekker; 1998. p. 507-39.

55. Hussain AA, Hirai S, Bawarshi R. Nasal absorption of natural contraceptive steroids in rats-progesterone absorption. J Pharm Sci 1981;70:466-7.

56. Hussain AA, Hirai S, Bawarshi R. Nasal absorption of propranolol in rats. J Pharm Sci 1979;68:1196.

57. Mahdi MH, Conway BR, Smith AM. Development of mucoadhesive sprayable gellan gum fluid gels. Int J Pharm 2015;488:12-9.

58. Djupesland PG, Skretting A. Nasal deposition and clearance in man: Comparison of a bidirectional powder device and a traditional liquid spray pump. J Aerosol Med Pulm Drug Deliv 2012;25:280-9.

59. Laube BL. Devices for aerosol delivery to treat sinusitis. J Aerosol Med 2007;20 Suppl 1:S5-17.

60. Aggarwal R, Cardozo A, Homer JJ. The assessment of topical nasal drug distribution. Clin Otolaryngol Allied Sci 2004;29:201-5.

61. Rudman KL, O'Brien EK, Leopold DA. Radiographic distribution of drops and sprays within the sinonasal cavities. Am J Rhinol Allergy 2011;25:94-7.

62. Hammarlund-Udenaes M, de Lange E, Thorne RG. Pharmacokinetic concepts in brain drug delivery in drug delivery to the brain. In: Physiological Concepts, Methodologies and Approaches. New York: Springer; 2014. p. 127-61.

63. Harmon BT, Aly AE, Padegimas L, Sesenoglu-Laird O, Cooper MJ, Waszczak BL, et al. Intranasal administration of plasmid DNA nanoparticles yields successful transfection and expression of a reporter protein in rat brain. Gene Ther 2014;21:514-21.

64. Kaye RS, Purewal TS, Alpar OH. Development and testing of particulate formulations for the nasal delivery of antibodies. J Control Release 2009;135:127-35.

65. Hardy JG, Lee SW, Wilson CG. Intranasal drug delivery by spray and drops. J Pharm Pharmacol 1985;37:294-7.

66. Haque S, Md S, Sahni JK, Ali J, Baboota S. Development and evaluation of brain targeted intranasal alginate nanoparticles for treatment of depression. J Psychiatr Res 2014;48:1-2.

67. Watson J, Wright S, Lucas A, Clarke KL, Viggers J, Cheetham S, et al. Receptor occupancy and brain free fraction. Drug Metab Dispos 2009;37:753-60.

68. Dinanath G, Padmini K, Dipak M, Namdeo J. Development of particulate mucoadhesive gel for intranasal delivery. Asian J Pharm Clin Res 2017;10:222.

69. Charlton ST, Davis SS, Illum L. Evaluation of bioadhesive polymers as delivery systems for nose to brain delivery: In vitro characterisation studies. J Control Release 2007;118:225-34.

70. Giuliani A, Balducci AG, Zironi E, Colombo G, Bortolotti F, Lorenzini L, et al. In vivo nose-to-brain delivery of the hydrophilic antiviral ribavirin by microparticle agglomerates. Drug Deliv 2018;25:376-87.

71. Deleu D, Hanssens Y. Current and emerging second-generation triptans in acute migraine therapy: A comparative review. J Clin Pharmacol 2000;40:687-700.

72. Mustafa E, Shaimaa NM, Al A. Design zolmitriptan liquisolid orodispersible tablets and their in vitro evaluation. Int J Pharm Pharm Sci 2016;9:297-303.

73. Zhang H, Lin CW, Donovan MD. Correlation between nasal membrane permeability and nasal absorption rate. AAPS PharmSciTech 2013;14:60-3.

74. Pelgrim GJ, Das M, Haberland U,Slump C, Handayani A, van Tuij S, et al. Development of an ex vivo, beating heart model for CT myocardial perfusion. Biomed Res Int 2015;2015:8.

75. Kozlovskaya L, Abou-Kaoud M, Stepensky D. Quantitative analysis of drug delivery to the brain via nasal route. J Control Release 2014;189:133-40.

76. Thornton-Manning JR, Dahl AR. Metabolic capacity of nasal tissue interspecies comparisons of xenobiotic-metabolizing enzymes. Mutat Res 1997;380:43-59.

77. Stevens J, Ploeger BA, van der Graaf PH, Danhof M, de Lange EC. Systemic and direct nose-to-brain transport pharmacokinetic model for remoxipride after intravenous and intranasal administration. Drug Metab Dispos 2011;39:2275-82. 